\title{
Organizational Ambidexterity: A Study in Brazilian Higher Education Institutions
}

\author{
Juliano Lima Soares ${ }^{1 *}$, Dálcio Roberto dos Reis², João Carlos da Cunha², Pedro José Steiner Neto²
}

\begin{abstract}
The purpose was to understand how the ambidexterity degree (exploration + exploitation actions) can explain the variance of the number of students. As theoretical foundation, it was considered the arguments proposed by March (1991) and Tuschman and O'Reilly III (2004) about organizational ambidexterity (balance of incremental and radical innovation initiatives). About the methodology, a quantitative approach was used, and the sample counted with 79 executives of higher education institutions (HEI). For data analysis, descriptive statistics, chi-square, cluster analysis, correlation analysis and multiple linear regression were used. As outcome, the confirmation that ambidexterity can explain variance of the number of students in $20.6 \%$. However, it was also observed that it cannot explain variation of the main index of teaching quality: General Course Index. Finally, there is a proposition of a maturity degree for ambidexterity, subdivided into four levels: I - Embryonic, II - Structured, III - Semi-developed and IV - Developed.
\end{abstract}

Keywords: Innovation management; Organizational ambidexterity; Higher education institutions.

Submitted: April 12 ${ }^{\text {th }}, 2018$ / Approved: July 10 $0^{\text {th }}, 2018$

\section{Introduction}

In 2004, Tushman and O'Reilly III published an article in Harvard Business Review, titled Ambidextrous Organizations, in which in its first few lines they present an analogy about a manager's ambidextrous capacity. The researchers describe that the Roman God Janus had two pairs of eyes, one of them to look at what was behind (past), and the other to look at what was yet to come (future). In the analogy pointed out by the authors, top executives should be able to focus their managerial efforts on improving already established products and processes while, at the same time, channel efforts and generate innovations that will define the company's future. Perhaps this is one of the most complex managerial challenges of an executive, and overcoming this may define the trajectory of his or her company.

In a more pragmatic way, several empirical works present outcomes and reflections of organizational ambidexterity. Three jobs can be highlighted. The first study is authored by Nicholas Tay (University of San Francisco) and Robert Lusch (University of Arizona) entitled Agent-based modeling of ambidextrous organizations: virtualizing competitive strategy, published in 2007 by IEEE Intelligent Systems. In its genesis, that research used definitions of ambidexterity defended by March and Tushman \& O'Reilly III (the same authors that inspired this research), and the element of interest of the investigation refers to the analysis horizon, using agent-based modeling (ABM). In the study, using the sophisticated technique ABM in their tests, Tay and Lusch (2007) observed that although an organization is ambidextrous in a turbulent market, it will not have a competitive advantage; however, such organization has more evolved learning capacity than other companies. In short, after the control of variables, as the authors proposed, due their exploration and exploitation skills, ambidextrous organizations learn $20 \%$ faster than other companies.
Second survey, conducted by authors Henry K. Kombo (Egerton University) and Peter K'Obonyo and Martin Ogutu (Nairobi University), is entitled Knowledge strategy and innovation in manufacturing firms in Kenya, published in October 2015 at International Journal of Scientific Research and Innovative Technology. In that paper, researchers investigated empirically for the purposes of strategic knowledge in innovative organizations. The study was transversal and its sampling was stratified - totaling 266 companies, representing 12 subsectors of manufacturing industry. The major hypothesis from Kombo, K'Obonyo and Ogutu (2015) emphasized that knowledge strategy has a positive effect on organizational innovation. To validate this hypothesis, authors used multiple regression technique. The research's outcome indicates that $24.2 \%$ of organizational innovation's variance is explained by variables derived from the knowledge strategy construct. Thus, researchers were able to conclude that knowledge strategy has a significant effect on organizational innovation, that is, companies that have higher levels of knowledge also generate more organizational innovations.

And, finally, the third study, by authors Paul Bierly and Paula Daly (Baylor University), entitled Alternative knowledge strategies, competitive environment and organizational performance in small manufacturing firms, that was published in 2007 at the Entrepreneurship Theory and Practice Journal. The research examined relationship between strategic knowledge, involving exploration and exploitation actions, and performance in small industries, including moderation variables involving external environment. Research results show that relationship between exploration and performance is linear and positive, and relationship between exploitation and performance is concave. The researchers also point out that outcomes provide valuable insight regarding the small manufacturers participating in the research, although it is not possible to generalize the study. On this regard, Bierly and Daly have suggested more in-depth studies of ambidexterity in service companies, which would make it easier to understand this much more complex sector of companies.

(1) Universidade Federal de Goiás (UFG), Brazil

(2) Universidade Positivo, Curitiba, Parana, Brazil

*Corresponding author: julianoltda@hotmail.com 
Analyzing the essence of all those research, such as relationship between ambidexterity and performance, organizational learning, data analysis and, hence, need for research on the topic in service providers, the research's problem is outlined: How much the ambidexterity degree (exploration + exploitation actions) can explain the variance of variable number of students (performance variable) in service companies, more specifically in higher education institutions (HEI)?

Based on the above research problem, general objective of this research was to understand how much the ambidexterity degree (exploration + exploitation actions) can explain the variance of the variable number of students in the investigated HEI.

About the theoretical justification of the work, it is important to indicate that the seminal research on the construct investigated in this study was published in 1991 in Organization Sciente journal, by March, with his paper entitled Exploration and exploitation in organizational learning. Since then, worldwide, several other researches have investigated this construct. In Brazil, when accessing the scientific bases - a) Scientific Electronic Library Online - Scielo, b) Scientific Periodicals Electronic Library - Spell and c) Commission of Improvement of Personnel of the Superior Level - Capes, being this last one holder of the bank of dissertations and theses of the Brazilian graduate programs - searching for ambidexterity and ambidextrous organizations (in the title, abstract or keywords), it is realized a timid diffusion of this theme. Four studies were found in Scielo, two studies published in Spell, and two papers at Capes (a thesis defended at Universidade Federal do Parana and a dissertation defended in the professional master's degree of Uninove University).

These results confirm the need for Brazilian scientific maturation in relation to the organizational ambidexterity construct. In view of this, theoretical justification of this research is to contribute to the scientific maturation on the ambidexterity phenomenon, especially because the study has been applied in service companies, thus, allowing for new and unprecedented reflections - with the intention of dilating the existing theory on the subject.

From the practical perspective, it is worth remembering that the sector studied by this research undergoes a deep change. With the political, economic and financial crises that began in Brazil in 2014, directors and deans of private HEI were forced to rethink several organizational practices, since the main Fund for Student Finance (FIES), that financed the students and guaranteed financial resources to HEI, has changed, the access became more restricted, reducing the number of enrolled students in the program. Although the higher education sector cannot measure, yet, the full impact of this change, HEI managers have begun to channel more efforts into managerial efficiency, closely monitoring organizational performance. That said, this research seeks to contribute to the management model of Brazilian HEI, reporting more pragmatically how relationship between the exploration and exploitation actions and the variation in the number of students works.

\section{Theoretical framework}

\section{Organizational ambidexterity}

Professor James March (Stanford University) published, in 1991, a seminal article entitled Exploration and exploitation in organizational learning, strengthening the concept of organizational ambidexterity. At the time, March (1991) showed concern from part of the researchers to develop studies aimed to investigate the adaptive process of an organization, emphasizing several and new possibilities (exploration) of investment, with clear and deep-rooted certainties (exploitation) of the resource consumption units. However, even earlier, in 1963, authors Cyert and March, based on theories of limited rationality, were already debating the balance of exploration and exploitation activities, emphasizing the role of goals.

The great dilemma that the theory proposes to cover, especially in organizational learning studies, refers to the impact of non-balancing between exploration and exploitation activities by part of the managers, thus, generating several consequences to the management and directly influencing the development and survival of an organization (MARCH, 1991).

About this dilemma, yet, Tushman and O’Reilly III (1996) present an even more complex trade-off, which is the managers' understanding of the short and long-term needs of an organization. For the researchers, the short-term needs refer to the search for the constant increase of adjustments or alignments in the productive process of the organization, that is, a permanent search for incremental innovations, and the longterm needs, in turn, it is the commitment to focus efforts accompanying and/or promoting revolutionary changes, called radical innovations.

Tushman and O’Reilly III (1996, p. 24) also emphasize that managers should be able to understand that "[...] contrasting managerial demands require managers to periodically destroy what has been created, in order to rebuild a new organization more appropriate for the next wave of competition or technology". Thus, ambidextrous organizations are those that can deal with this paradox, and that seek to consolidate the abilities to simultaneously develop the actions of incremental (exploitation) and radical (exploration) innovations to better position them in their business environment (MARCH, 1991; TUSHMAN \& O’REILLY III, 1996).

Some concepts are essential to understand organizational ambidexterity. Next, definitions and characteristics of incremental innovations (which from now on are called exploitation) and the radical innovations (called exploration) are presented.

\section{Exploitation actions}

Activities of exploitation (incremental innovations) are those that seek to implement, fill and encourage the process of change in search of a constant improvement, being: a) qualitative change in existing product, b) improvement in an industry process, c) opening of a new market to sell existing products; and (d) development of new sources of raw material or other inputs (OCDE, 1997). 
Tushman and O’Reilly III (2004) explain that exploitation actions are indispensable for a company to thrive, because these are the practices that will enable the organization to constantly evolve, seek improvements in its products and operations, and, then, operate more efficiently. March (1991) points out that an organization with high level of exploitation is able to refine its operations, obtaining greater efficiency in the selection, production, implementation and execution of its routines. Popadiuk (2015, p. 30), in turn, indicates that the exploitation activity is the "[...] usage of tangible and intangible resources [...]. Because of the exploitation orientation, organization develops activity regarding refinement, choices and improvement of processes, routines and personnel."

In short, organizations focused on exploitation actions generate successive improvements in an existing process or product, in order to enhance the company's added value, influencing the general rate of productivity growth, resulting from increased technical efficiency, productivity, precision in the processes, among other elements that seek to achieve better quality of the products, together with the reduction of costs or the increase of profit margins (PEREZ, 2004).

\section{Exploration actions}

With respect to exploration actions (radical innovation), March (1991) defines them as initiatives, in an organization, that strive for research, experimentation and discovery of a new technology. Tushman and O'Reilly III (2004) indicate that exploration actions are essential for the development of an organization, since through them companies will achieve solid technological advances, leading to deep changes in their components (products or services), productive processes, and even in their business.

Popadiuk (2015, p. 28) contributes by pointing out that exploration actions in an organization refer to "[...] research, search, discovery, study, observation, entrepreneurship, survey, prospecting, and experimentation $[. .$.$] is the search and creation of new knowledge that can$ be originated from both external and internal environment." The Oslo Manual (OCDE, 1997, p. 70), on the other hand, describes that these actions have a "[...] concept centered on the impact of innovations [...] impact can, for example, change the market structure, create new markets or making existing products obsolete".

Reis et al. (2011), when discussing the theme, conceptualize the action of exploration as outcome of an idea that results in an absolutely new product, service, process or business, not yet available in the market. Its introduction in the market generates a structural break, establishing new segment, industry and market.

Thus, it is possible to conclude that exploration actions contribute to generation of a new product or process, capable of initiating a new technological course and, in some cases, being able to consolidate and conceive a whole new industry. This innovation is directly related to a rupture in the economy, being that, after the break, little by little, the technology will obtain a market position (PEREZ, 1998).
After knowing the difference between exploitation and exploration, it is important to emphasize that the strategies assumed by the organization tend, of course, to guide the company towards the development of a type of innovation. However, some organizations that have a more sophisticated management model are able to equalize the conceptions of their innovations, acting in a balanced and orchestrated way on both fronts (exploitation and exploration actions). These organizations, therefore, are known as ambidextrous organizations.

\section{Ambidextrous organizations}

The definition of ambidextrous organizations presented by March (1991) defends that there are organizations that can deliberately maintain a balance between exploitation and exploration actions, therefore, being classified as ambidextrous. Tushman and O'Reilly III (2004) complement it, by reaffirming that ambidextrous organizations are those that can balance their efforts in exploitation and exploration. They point out, however, that because of the complexity of meeting these two perspectives, it is necessary for organizations to establish different strategies for managing their structures, processes and culture.

The secret of ambidextrous organizations is, therefore, the excellence for conducting simultaneously exploration and exploitation actions. With this know-how, organizations can balance / orchestrate their efforts and organizational resources, keeping ahead of their competitors. According to the Schumpeterian theory, organizations that innovate perform better than companies that do not innovate, and ambidextrous organizations perform better than companies that innovate from only one perspective, such exploitation or exploration (SCHUMPETER, 1985).

While on the subject, finally, a critical point of the above theory relates to the use of a measurement scale that is capable of measuring the level of organizational ambidexterity present in the management model of a given company. The scale used to measure the ambidexterity of the organizations investigated in this research is the scale developed by Lubatkin et al. (2006). This choice is justified by a) extent of the scale, both in theoretical and empirical perspectives, b) best adaptation to the economic segment of the companies investigated.

Hence, this subsection concludes the theoretical basis of this research. Next, the research methodology is presented, detailing the problem's specification, as well as delimitation and design of the research.

\section{Methodology}

This section presents the delimitations of the nature (ontology) and the phenomenon's knowledge (epistemology) referring to this research, mainly the ways the researcher has chosen to access, to study and to analyze primary data in the investigation. To facilitate the understanding of the adopted methodology, Descriptors of Research Planning, as described by authors Cooper and Schindler (2003), are indicated in Box 1, with the key aspects of the research. 
Box 1: Descriptors of Research Planning.

\begin{tabular}{l|c}
\hline Category & Category \\
\hline $\begin{array}{l}\text { Degree to which research questions were crystallized } \\
\text { (Level of elaboration of research questions) }\end{array}$ & Exploratory study \\
\hline Method of data collection & Question / Communication \\
\hline $\begin{array}{l}\text { Researcher's power to produce effects on the variables being studied } \\
\text { (Control of variables by the researcher) }\end{array}$ & Ex-post-factor \\
\hline Study objective & Descriptive \\
\hline Time dimension & Transversal \\
\hline Topic scope - amplitude and depth & Statistical study \\
\hline Research environment & Field environment \\
\hline People's perceptions about the research activity & Real routine \\
\hline Population and sample & Censitary by adhesion \\
\hline Research subject & Director General or Dean \\
\hline Data collection feature & Online questionnaire available on \\
\hline Data collection period & the Survey Monkey \\
\hline
\end{tabular}

Source: Adapted from Cooper and Schindler (2003, p. 129).

Regarding population and sample, it is important to highlight that the investigated HEI are part of the same Brazilian educational group, and the sample was censitary based on adherence, that is, questionnaire was sent to the entire population (110 Directors or Deans), with participation of the interested ones. Research subjects were all those who decide on the HEI's allocation of resources; these, in turn, assume roles of Director General, in the case of colleges, and Dean, in the case of university centers and universities. Data collection period is between June 27, 2016 and July 12, 2016.

Before addressing the research hypothesis, it is necessary a conceptual approach. Martins and Theóphilo (2009, p. 30) define hypothesis as "[...] a proposition, with sense of conjecture, of supposition, of anticipation of response to a problem, that can be accepted or rejected by the research results". The hypothesis of this investigation, therefore, was:

Research hypothesis: The ambidexterity degree (exploration actions + exploitation actions) can explain the variance of the variable number of students in the investigated HEI.

Context: Empirical studies on ambidexterity constantly seek to investigate its relation to organizational performance. In this case, what is studied is how organizational ambidexterity can explain one given performance variable in service companies, and for this research, the chosen variable is the number of enrolled students. The choice of this variable is surgical, since it will derive financial and teaching quality results of a HEI.
Statistical tests: Correlation, Multiple Linear Regression.

Regarding the measurement scale, it should be noted that in order to measure the organizational ambidexterity phenomenon there were two factors: a) exploration actions and b) exploitation actions. Each factor had seven variables, each one measured on a five-point Likert scale, considered as a scale of intensity, ranging from 1) Very Small; 2) Small; 3) Average; 4) Big and 5) Very Big. By adding up the score of each variable, it was possible to totalize up to thirty-five points per factor. The variables used were:

Exploration actions - key question:

Regarding the actions of your unit, related to DEVELOPMENT and FORECASTING NEW TECHNOLOGIES, in the last three years, what was the INTENSITY of your company for:

(+)15.1 Searching for "out of the box" technological solutions, that is, search for solutions outside the company's limits, researching technologies different from the current ones?

(+)15.2 Explaining the company's performance due to the exploitation of innovative technologies, that is, basing its success in the ability to explore new technologies?

(+)15.3 Focusing on the creation of new products and/or services? (+)15.4 Looking for creative and differentiated ways to meet the students' needs?

$(+) 15.5$ Using new products to operate in new markets?

$(+) 15.6$ Using new services to operate in new markets?

(=) SUMMATION FORMS THE EXPLORATION DEGREE (EXP) 
Exploitation actions - key question:

Regarding the actions of your unit, related to IMPROVEMENT AND EXPLOITATION OF CURRENT TECHNOLOGIES, in the last three years, what was the INTENSITY of your company for:

(+) 16.1 Seeking to gradually improve the quality of products and services? (+) 16.2 Seeking to gradually reduce the costs of products and services? (+) 16.3 Seeking to gradually increase the reliability of products and services?

(+) 16.4 Seeking to increase the levels of automation in operations?

(+) 16.5 Researching frequently the satisfaction of current students?

(+) 16.6 Developing offerings of products or services, carefully observing characteristics of current students?

(+) 16.7 Seeking to strengthen and deepen relationship with current students?

(=) SUMMATION FORMS THE EXPLOITATION DEGREE (EXP)
By summation (EXP + EXT = AMBIDEXTERITY DEGREE), it is found the AMBIDEXTERITY DEGREE (AMBD), according to guidelines of Lubatkin et al. (2006) and Scandelary and Cunha (2013). At this moment, the section about research methodology is concluded. Next, results are presented, divided into a) characterization of the managers and investigated HEI, b) organizational ambidexterity, c) proof of the research hypothesis, and d) analysis beyond the research hypothesis.

\section{Data presentation and data analysis}

Before presenting the survey data, it is necessary to present the test results referring to the scale quality used in the research. These tests, as well as their results, are briefly presented in Box 2 .

Box 2: Scale Quality. Source: Author, based on Marôco, 2016.

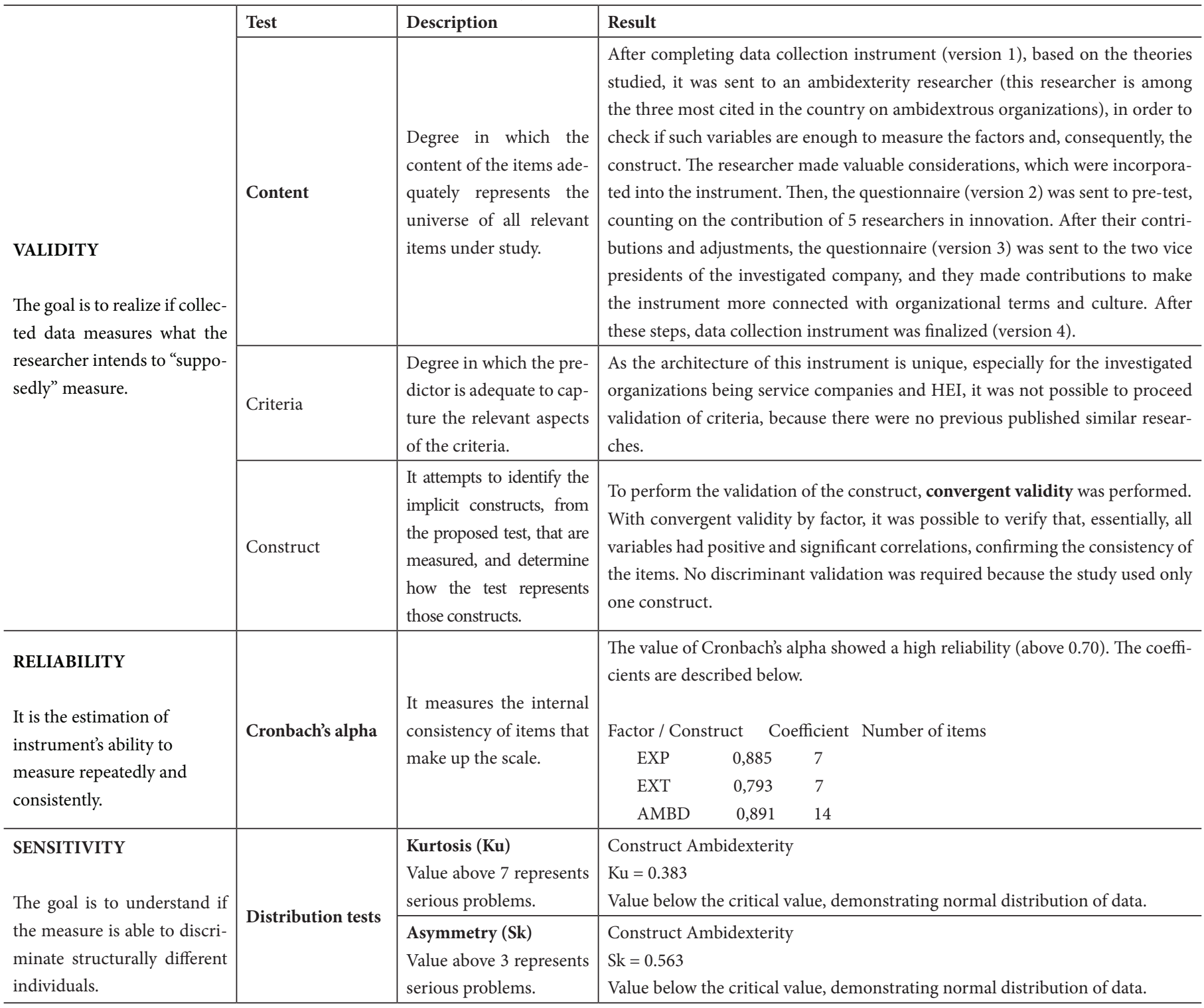


After presenting the consistency of the data collection instrument, main findings of the research are presented next. The presentation is divided in three blocks, being 1) characterization of managers and investigated HEI, 2) Ambidexterity degree, and 3) Analysis of Research Hypotheses.

\section{Characterization of managers and investigated HEI}

From the answers to the research questions, it was possible to verify that the respondent managers are, for the most part, men $(63.3 \%$ of the total respondents). In $78.5 \%$ of cases, managers are between 36 and 54 years old. Regarding their education, $48.1 \%$ have a Master's degree, and $40.5 \%$ have a postgraduate degree (Sensu Lato course). A significant number of managers have background in human sciences (38\%) or social studies $(32.9 \%)$. The largest share $(54.4 \%)$ of them work in higher education between 11 and 20 years, and $54.4 \%$ have no more than 10 years of work in the company.
Regarding characteristics of the investigated HEI, more specifically the type of academic organization, there were 72 colleges, 4 university centers and 3 universities. In general, these HEI represent 652,470 students, 1,338 higher education courses, 9,382 technical-administrative staff and 10,674 teachers.

After knowing the respondents profile and structure of the investigated HEI, the following are the main results from the organizational ambidexterity construct.

\section{Ambidexterity degree}

As presented in the theoretical framework, organizational ambidexterity occurs when a company is able to orchestrate actions of exploration and exploitation (March, 1991). Based on the model of analysis proposed by Lubatkin et al. (2006) and adopted by Scandelari (2011), average of responses per variable are indicated in Table 1. It should be noted that the weight of each variable orbits between 1 and 5 points.

Table 1: Variables and Factors. Source: Author.

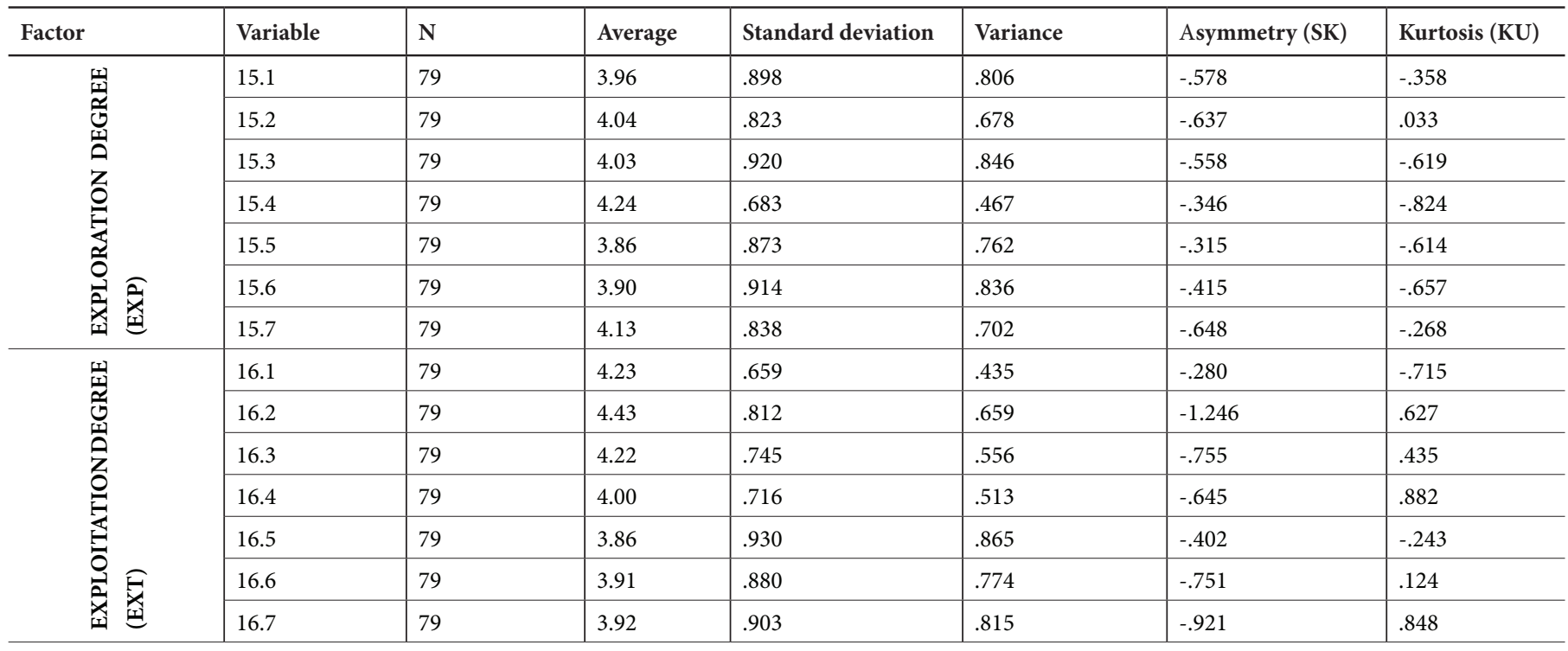

By checking these data, especially EXP factor, it can be noticed that the variable with the highest average was 15.4 (Looking for creative and differentiated ways to meet the students' needs), totaling 4.24. It is important to highlight that this variable was the one that obtained the lowest variance and, consequently, the best standard deviation, that is, there was a greater homogeneity among the respondents. Other variables that stood out were: 15.2 (Explaining the company's performance due to the exploitation of innovative technologies, that is, basing its success in the ability to explore new technologies) and 15.3 (Focusing on the creation of new products and/or services), with average of 4.04 and 4.03 , respectively.

In turn, about the analysis of EXT factor, the variable that obtained lower average was to 16.2 (Seeking to gradually reduce the costs of products and services), with average of 4.43 . This same variable obtained the lowest variance (0.435) and the lowest standard deviation (0.659). Subsequently, variables 16.1 (Seeking to gradually improve the quality of products and services) and 16.3 (Seeking to gradually increase the reliability of products and services) obtained the second and third largest averages, with values 4.23 and 4,22, in due order.

It is worth mentioning that, when analyzing the asymmetry (SK) column, all variables are below the critical value (3.00). Also, the same occurs when analyzing the data of the kurtosis (KU) column, whose critical value is 7.00 . With these results, it is possible to conclude that the data distributions are considered normal.

Next, after knowing the averages of each variable, weights of the factors are indicated. For that, the scores of each variable were added per company, thus, forming the EXP and EXT factors. The possible dispersion of data would be 7 to 35 points. To better synthesize the data, Chart 1 is presented, in a composition of two axes (as XXX and XXX, 2011 suggests). Loads from Y axis represent Exploration Level (EXP), with Exploitation Level (EXT) on X axis. To form the four possible taxonomies, data of the table highlighted in the section that deals with the methodology are used. 
Chart 1. Ambidexterity Level. Source: Author.

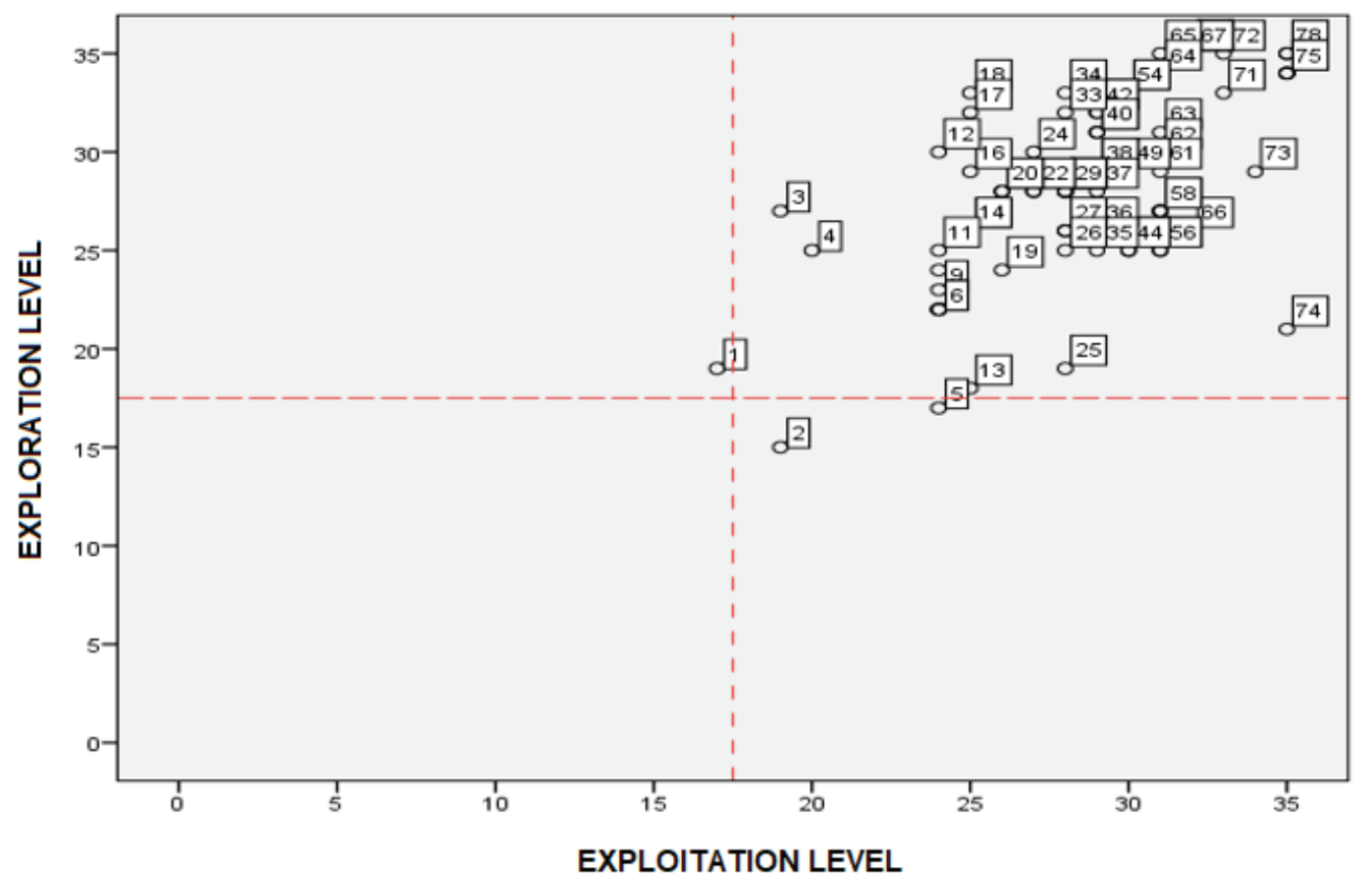

According to the chart, it is possible to verify that, with the exception of three HEI, all institutions were concentrated in the quadrant of Ambidextrous Organizations. Thus, evidences are:
a) No HEI was considered Non-Innovative Organization;
b) Only one organization is strongly oriented just to Exploration actions (Case \#1);

c) In the case of organizations that are heavily targeted just for Exploitation actions, there are only two institutions, cases \#2 and $\# 5$;

d) In the quadrant of Ambidextrous Organizations, there are the other institutions (76 cases).

After knowing the ambidexterity degree of the investigated HEI, results of the hypothesis tests of the research are found.

\section{Proof of research hypothesis}

The research hypothesis sought to show that "the ambidexterity degree (exploration actions + exploitation actions) can explain the variance of the variable number of students in the investigated HEI". To prove this hypothesis, it was used the Correlation Analysis and the Multiple Linear Regression.

Correlation analysis is, according to Dancey and Reidy (2007), a test that seeks to understand if two variables (or factors) are associated or correlated. According to Fávero, Belfiore and Chan (2009, p. 346), linear regression has the purpose of "[...] study the relationship between two or more explanatory variables, which are presented in linear form, and a dependent variable".
In this research, the dependent variable in the model is the number of students reported by the organization, that is, secondary data. The choice made, for the variable to be explained, stems from the fact that this is one of the most important performance variables of an educational institution, since it directly influences the financial, managerial and qualitative indicators of any HEI.

In order to increase the reliability of the findings, it is worth noting that all the assumptions of the linear regression cited by Fávero, Belfiore and Chan (2009, p. 346 apud KENNEDY, 2003) were analyzed and respected, being them:

a) Dependent variable is a linear function of a specific set of variables and error;

b) Expected value of the error term is zero;

c) Error has normal distribution and does not present auto correlation or correlation with any variable X;

d) Observations of the explanatory variables can be considered fixed and in repeated samples;

e) There is no exact linear relationship between explanatory variables and there are more observations than explanatory variables.

By performing the Regression test, it was possible to verify that the correlation index of EXT and EXP compared to the number of students was 0.454 . Using the criteria of Dancey and Reidy (2007), the correlation is considered moderate, that is, there is a moderate relationship between the EXP and EXT variables and the number of students.

Regarding Multiple Linear Regression test, before presenting the coefficient, it should be noted that the model obtained a sig value lower 
than 0.005 , being interpreted as a consistent model. About the variance explained, the factors EXPLORATION DEGREE (EXP) and EXPLOITATION DEGREE (EXT) explain in 20.6\% the variance of the variable NUMBER OF STUDENTS. For some sciences, such as engineering and health, this explained variance is considered low; however, considering that these two factors can explain $20.6 \%$ of the variation in the number of students of the investigated HEI, this value becomes significant.

In this way, it is possible to conclude, finally, that the initial research hypothesis, which conjectured that "the ambidexterity degree (exploration actions + exploitation actions) can explain the variance of the variable number of students in the investigated HEI" was duly confirmed.

\section{Analysis beyond hypothesis}

The analisys of Chart 1 allows to visualize that, in $96 \%$ of the cases, investigated HEI were considered ambidextrous organizations. However, although all HEI are part of the same company, it is seen that there was a great dispersion among the researched cases. On this respect, a proposition was raised for the existence of different stages of ambidexterity, that is, there are HEI that work at a more evolved ambidexterity level than others - being this phenomenon preliminarily called Maturity Degree of Organizational Ambidexterity.

To materialize this proposition, a K-means cluster analysis was performed, dividing the population into 4 groups. Before presenting the groups, however, it is important to note that the researchers performed three grouping tests, which are explained below.

1) In the implementation of Two Step Cluster, although the Quality cluster was higher than 0.5 , indicating a good clustering, SPSS proposed the creation of only two clusters, so it was not possible to establish a maturity degree about the ambidexterity;

2) Hierarchical Cluster was not used, since it is clear the theory that guides the research;

3) In the realization of K-means, test was executed, initially, to generate 5 clusters. On the occasion, two clusters were generated with 2 cases in each of them and, when analyzing the average values of the cases, little difference was noticed, that is, it would not be necessary to divide them into two groups.

After the explanation above, Table 2 presents the average values of the ambidexterity degree of each formed cluster.

Table 2: Cluster Creation.

\begin{tabular}{lllll}
\hline \multirow{2}{*}{ Grouping variable } & \multicolumn{2}{l}{ Cluster (Group) } & \\
& 1 & 2 & 3 & 4 \\
\hline Ambidexterity degree (centroids) & 57 & 39 & 48 & 67 \\
Quantity of cases per cluster & 46 & 4 & 12 & 17 \\
\hline
\end{tabular}

Source: Author.
After SPSS generated the centroids and grouped the cases over them, 4 clusters were formed. In theory, they represent the level of maturity of the ambidexterity in the investigated companies, and each group was named as follows:

Level I - Embryonic (Group 2): it represents the first stage of ambidexterity. Although the organization is already considered ambidextrous, it still needs to potentiate / encourage more exploration and exploitation actions;

Level II - Structured (Group 3): in the second stage of the ambidexterity, exploration and exploitation actions are more elaborate and structured;

Level III - Semi-developed (Group 1): in the third stage of ambidexterity, exploration and exploitation actions respect a continuous flow;

Level IV - Developed (Group 4): the fourth stage of ambidexterity is the most developed stage, in which exploration and exploitation actions are constant, permanent, with consistent and well-structured projects, often refined and evaluated.

In order to verify if maturity levels of ambidexterity (ordinal variable) had some relation or interaction with a set of other variables (nominal or ordinal), Pearson's chi-square test was performed, considering a $p$ value of 0.05 . The following results were obtained:

Table 3: Analysis of Pearson's chi-square test. Source:

\section{Pearson's chi-square test}

\begin{tabular}{ll}
\hline Analyzed Variables & sig \\
Gender ${ }^{*}$ Ambidexterity level & .945 \\
\hline Age group * Ambidexterity level & .144 \\
\hline Education degree ${ }^{*}$ Ambidexterity level & .912 \\
\hline Educational background ${ }^{*}$ Ambidexterity level & .886 \\
\hline Working time with Higher Education * Ambidexterity level & .703 \\
\hline Working time in the company * Ambidexterity level & .041 \\
\hline \multicolumn{2}{c}{ Author. }
\end{tabular}

With the above data, it is possible to realize that the only variable that has an interaction or dependence relationship with the ambidexterity levels proposed by the work is the variable "working time in the company". To further analyze the data, it is also verified that the longer a person works in the company, the greater the average ambidexterity degree. Chart 2 allows an easier understanding of this evidence. 
Chart 2: Average working time and ambidexterity degree.

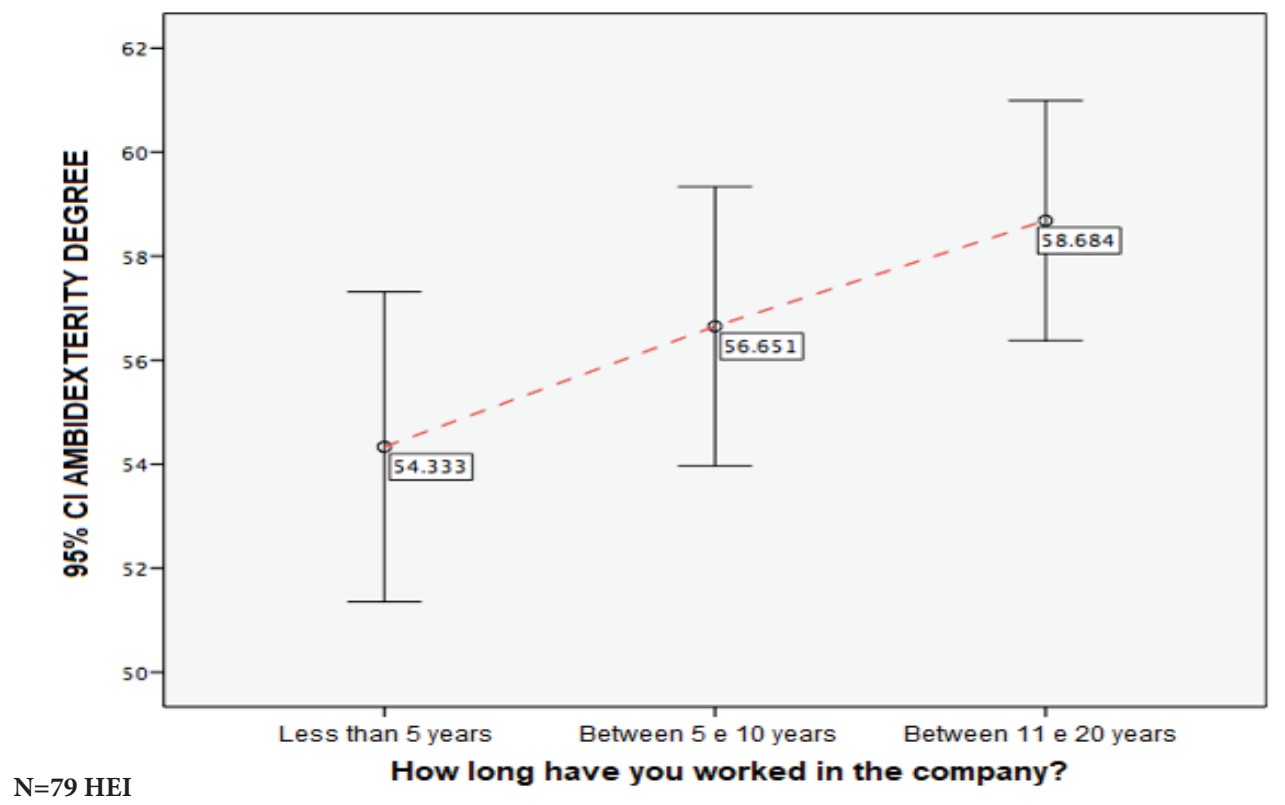

Source: Author.

Another investigated aspect was how much EXT and EXP factors could explain the General Course Index (GCI). GCI is the most important quality indicator of Brazilian HEI, being, in theory, updated annually. The effort, at this moment, is not to dissect the indicator, but to present how much of its variance can be explained by the studied construct. Considering the current IGC of each investigated HEI (July 2017), it was possible to notice that EXP and EXT factors explain $0.20 \%$ of the IGC variance of HEI. That is, less than $1 \%$ of the variation of the IGC is explained by exploration and exploitation actions of HEI, thus, generating a series of reflections, such as the two highlighted statements below.

a) The innovative ability of HEI is not privileged among the evaluation criteria used by the Brazilian Ministry of Education;

b) GCI, as indicator, is composed of so many other variables that explain its variance is a great challenge for any quantitative research.

Finally, the data presentation and analysis presentation section is concluded and, next, concluding remarks of the research are presented, highlighting its general objective, research hypothesis, main findings and, then, indications for future research.

\section{Concluding remarks}

The general goal of the research was to understand how the ambidexterity degree (exploration actions + exploitation actions) can explain the variance of the variable number of students (performance variable) in HEI. Investigated HEI are part of the same economic group, and the subjects of the research were General Directors or Deans of these institutions. After data collection, there were 79 valid cases, among these 72 colleges, 4 university centers and 3 universities.

The research hypothesis was confirmed by multiple regression statistical test (sig less than 0.005), thus, showing that the exploration and exploitation actions of HEI can explain the variance of the variable number of students in $20.6 \%$.

Another contribution of this research is the proposition of taxonomies involving ambidexterity. Up to the present study and according to the theoretical framework studied, there were only 4 taxonomies to study the ambidextrous organizations, being a) non-innovative company, b) company with high level of exploration, c) company with high level of exploitation, and d) ambidextrous companies. However, as the study was carried out in companies that are part of the same company, many of them classified as ambidextrous organizations, but with a large dispersion of data, this led to believe in the existence of a MATURITY DEGREE OF AMBIDEXTERITY. As to this degree, ambidextrous organizations can be reclassified through their ambidexterity levels (centroids), which, in this research, were defined as Level I - Embryonic; Level II - Structured; Level III - Semi-developed; Level IV - Developed.

In addressing the research limitations, there is the widespread inability of research findings. This means that the conclusions are applied only to the sample investigated, since the time horizon refers to a cross-section analysis exclusive for the period between 2013 to 2016; finally, although the subject of the research was the HEI's main manager (Director General or Dean), top executive, there was only one response per company investigated. 
As suggestions for future research, it is indicated:

a) Replication of the research for public and private HEI: when applying the same data collection instrument in public and private HEI (with and without capital available on the Bovespa - Brazilian Stock, Mercantile \& Futures Exchange), it will be possible to compare the similarities and heterogeneities of multiple regression coefficients, allowing to understand in which of the three groups this model better fits;

b) Maturity Degree of Ambidexterity: it is suggested replication of the data collection instrument, as well as the classification among the levels of organizational ambidexterity of future companies to be investigated; afterwards, an in-depth qualitative research would be conducted with companies of one of the levels, seeking to understand the operational singularities between them and, consequently, the differences between levels;

c) Relationship between the Ambidexterity Degree and Competitiveness Degree: it is suggested to investigate the relationship between the organizational ambidexterity construct and competitiveness, since both theories are associated to the explanation of the variation of organizational performance; for this research, it is suggested to use a more sophisticated statistical test, such as analysis of structural equations.

\section{References}

Bierly, P. E.; Daly, P. S. (2007) Alternative knowledge strategies, competitive environment, and organizational performance in small manufacturing firms. In Entrepreneurship Theory and Practice .pp. 493516. https://doi.org/10.1111/j.1540-6520.2007.00185.x

Ministério da Educação. Instituto Nacional de Estudos e Pesquisas Educacionais Anísio Teixeira. (2015). Censo da Educação Superior 2013: resumo técnico. Brasília.

Cooper, D. R; Schindler, P. S. (2003). Métodos de pesquisa em administração. Porto Alegre: Bookman.

Dancey, C. P.; Reidy, J. (2006). Estatística sem matemática para psicologia: usando SPSS para Windows. 3. ed. Porto Alegre: Artmed.

Fávero, L.P.; Belfiore, P.; Silva, F.L.; Chan, B.L. (2009). Análise de dados: modelagem multivariada para tomada de decisões. 5 . ed. Rio de Janeiro: Campus / Elsevier.

Lubatkin M. H.; Simsek, Z. Y.; Veiga, J. F. (2006). Ambidexterity and performance in small-to medium-sized firms: the pivotal role of top management team behavioral integration. Journal of Management, 32, 646-672. https://doi.org/10.1177/0149206306290712
March. J. (1991). Exploration and exploitation in organizational learning. Organization Science, 2. 71-87. https://doi.org/10.1287/ orsc.2.1.71

Marôco, J. (2014) Análise de equações estruturais: fundamentos teóricos, software \& aplicações. 2. ed. Pêro Pinheiro: Cafilesa.

Marôco, J. (2016) Teaching notes. Portugal.

Martins, G. A; Theóphilo, C. R. (2009) Metodologia da investigação científica para ciências sociais aplicadas. São Paulo: Atlas.

Nascimento, T. C.; Cherobim, A. P. M. S.; Mendonça, A. T. B. B. (2013) Escalas de capacidade inovadora: uma revisão sobre proposições para avaliação de ambidestralidade em organizações. XXXVII Encontro da ANPAD, Rio de Janeiro.

O'reilly, C. A; Tuschman, M. L. (2004). The ambidextrous organization. Harvard Business Review, 82(4). 78-81.

OCDE Organização de Cooperação e Desenvolvimento Econômico. (2017, July, 18). Manual de Oslo: Diretrizes para a coleta e interpretação de dados sobre inovação. 3. Ed. [online]. From http://www.finep. gov.br/images/apoio-e-financiamento/manualoslo.pdf

Perez, C. (2004) Revoluções tecnológicas, troca de paradigmas e mudanças sócio institucionais. In: Reinert, E. (Ed.) Globalization, economic development and inequality: an alternative perspective. (pp. 217-242). Cheltenham, UK and Northampton, USA: Edward Elgar.

Popadiuk, S. (2015). Exploração, explotação e ambidestria: inovação para a geração de valor. São Paulo: Mackenzie.

Reis, D.; Carvalho, H. G. R.; Cavalcante, M. B. (2011) Gestão da inovação. Curitiba: Aymará.

Scandelarli, V. R. N. (2011) Inovação e sustentabilidade: ambidestralidade e desempenho sustentável na indústria eletroeletrônica. Dissertation (Doctorship). Universidade Federal do Paraná - UFPR.

Scandelarli, V. R. N; Cunha, J.C. (2013) Ambidestralidade e Desempenho Socioambiental de Empresas do Setor Eletroeletrônico. RAE, São Paulo, v. 53, n. 2, mar.-abr. 183 - 198.

Schumpeter, J. A. (1985) Teoria do desenvolvimento econômico. São Paulo: Nova Cultural.

Tushman, M. L; O'reilly, C. A. (1996). Ambidextrous organizations: managing evolutionary and revolutionary change. California Management Review. https://doi.org/10.2307/41165852 
